\title{
Maximal Inspiratory and Expiratory Pressures in Men with Chronic Obstructive Pulmonary Disease: A Cross-Sectional Study
}

\author{
Veena Kiran Nambiar, Savita Ravindra, B. S. Nanda Kumar ${ }^{1}$ \\ Departments of Physiotherapy and ${ }^{~}$ Community Medicine, Ramaiah Medical College and Hospitals, Bengaluru, Karnataka, India
}

\section{Abstract}

Introduction: Respiratory muscle dysfunction is a cardinal feature in chronic obstructive pulmonary disease (COPD) contributing to decreased exercise capacity and pulmonary function test (PFT) limitation with progression of the disease. Maximal inspiratory pressure (MIP) and maximal expiratory pressure (MEP) are reliable parameters for assessing the respiratory muscle strength. Aims: This study aims to measure maximal inspiratory and expiratory pressures in male COPD patients, to determine their correlates, and to study the relationship between the severity of COPD and respiratory muscle strength. Patients and Methods: This was an observational, cross-sectional study. A total of 100 males, who were known COPD patients and who were clinically stable, were recruited. Both inpatients and outpatients were studied. Spirometric PFT test was done, and MIP and MEP were measured using respiratory pressure meter. Descriptive statistics and Pearson's correlation were used. Results: The mean ( \pm standard deviation) MIP and MEP were $47.73( \pm 19.6) \mathrm{cm} \mathrm{H}_{2} \mathrm{O}$ and $60.76( \pm 11.6) \mathrm{cm} \mathrm{H}_{2} \mathrm{O}$, respectively. MIP and MEP showed a highly significant correlation $(P<0.001)$ with forced expiratory volume at $1 \mathrm{~s}\left(\mathrm{FEV}_{1}\right)$ and forced vital capacity. The correlation of MIP and MEP with FEV 1 shows a positive linear trend, and the MEP values were higher than MIP values. There was a decrease in MIP and MEP with increasing severity of COPD. Conclusion: MIP decreases with progression of the disease, and thus, inspiratory muscle training should be included in a pulmonary rehabilitation program.

Keywords: Chronic obstructive pulmonary disease, maximal expiratory pressure, maximal inspiratory pressure, pulmonary function test

\section{INTRODUCTION}

According to the World Health Organization, it is estimated that chronic obstructive pulmonary disease (COPD) will be the third-most common cause of death and fifth-most common cause of disability in the world by $2020 \cdot{ }^{[1]}$ COPD is considered as a respiratory disease with multiple systemic pathological components. Musculoskeletal system is often involved in patients with COPD, contributing to decrease in effort capacity and quality of life ${ }^{[2]}$ In this context, inspiratory muscle function is frequently affected. This may be due to chronic systemic inflammation inducing pathological changes in the thoracic cage or producing structural alteration in the respiratory muscles. ${ }^{[3-5]}$ Decrease in inspiratory muscle function represents an important prediction factor for the survival rate in COPD patients. ${ }^{[6]}$

The imbalance between respiratory muscle function and load is an important determinant of dyspnea and hypercapnia. ${ }^{[7]}$ While

\begin{tabular}{|l|l|}
\hline \multicolumn{2}{|c|}{ Access this article online } \\
\hline Quick Response Code: & Website: \\
\hline & www.ijrconline.org \\
\cline { 2 - 2 } & \\
\hline
\end{tabular}

inspiratory muscles reach their optimal force-length relationship at low pulmonary volumes, the expiratory muscles reach it at high lung volumes ${ }^{[8]}$ Respiratory muscle dysfunction is a cardinal feature of acute and chronic respiratory failure in COPD. ${ }^{[9]}$ Hypercapneic respiratory failure following inspiratory muscle weakness is found to be the leading cause of death in COPD patients. ${ }^{[10,11]}$ As the most of the lung and airway derangements are irreversible in COPD, all therapeutic interventions must be aimed at strengthening the respiratory muscles. ${ }^{[7]}$

The respiratory muscle strength is best assessed regarding maximal inspiratory pressure (MIP) and maximal expiratory

Address for correspondence: Dr. Veena Kiran Nambiar, Department of Physiotherapy, Ramaiah Medical College and Hospitals, Bengaluru - 560 054, Karnataka, India. E-mail: veenakiran_nambiar@yahoo.co.in

This is an open access journal, and articles are distributed under the terms of the Creative Commons Attribution-NonCommercial-ShareAlike 4.0 License, which allows others to remix, tweak, and build upon the work non-commercially, as long as appropriate credit is given and the new creations are licensed under the identical terms.

For reprints contact: reprints@medknow.com

How to cite this article: Nambiar VK, Ravindra S, Kumar BS. Maximal inspiratory and expiratory pressures in men with chronic obstructive pulmonary disease: A cross-sectional study. Indian J Respir Care 2018;7:88-92. 
Nambiar, et al.: Respiratory muscle pressures in male COPD patients

pressure (MEP). MIP is the maximum negative pressure that can be generated from one inspiratory effort starting from functional residual capacity (FRC) or residual volume (RV). MEP measures the maximum positive pressure that can be generated from one expiratory effort starting from total lung capacity (TLC) or FRC.

This study aimed to measure the respiratory muscle strength using MIP and MEP in clinically stable male COPD patients, to determine the correlates for MIP and MEP, and to study the relationship between severity of COPD (GOLD Criteria) and respiratory muscle strength.

\section{Patients and Methods}

This was a cross-sectional, observational study. Convenience sampling was used. Participation was purely on voluntary basis. After obtaining informed consent, 100 males, who were known COPD patients, both inpatients and outpatients, and who were clinically stable, were recruited. Ethical clearance was obtained from the Ethical Review Board of the Institution. This study was conducted on male patients only to avoid intergender differences in MIP and MEP. A total of 99 patients completed the MIP and MEP assessment phase. There was a dropout of one patient due to noncompliance and thus incomplete data.

Patients with primary muscular/neuromuscular diseases and clinically significant comorbidities that could affect the test results and COPD patients in acute exacerbation were excluded from the study.

For all patients, demographic data were obtained. Spirometric pulmonary function (PFT) was done using Schiller machine. Best of the three successive test readings were taken as a final result, and the primary values, i.e., forced vital capacity (FVC), forced expiratory volume in the $1 \mathrm{~s}\left(\mathrm{FEV}_{1}\right)$, and $\mathrm{FEV}_{1} / \mathrm{FVC}$ ratios were recorded. Anthropometry was done by measuring weight in kilogram $(\mathrm{kg})$ and height with a stadiometer and body mass index (BMI) was calculated according to the formula $\mathrm{kg} / \mathrm{m}^{2}$. MIP and MEP were determined using portable pressure meter (Micro respiratory pressure meter). MIP was measured from FRC or RV, and MEP was measured starting from TLC. All recordings were taken in the sitting posture. Maximum of three trials were given with an interval of $1 \mathrm{~min}$ between the trials for each subject. The highest value was accepted for computation.

The collected data were coded, tabulated, and introduced to PC using SPSS 16 (SPSS Inc., SPSS for Windows, Chicago). Descriptive statistics were used to obtain mean and standard deviation $( \pm \mathrm{SD})$ for parametric numerical data, namely, age, height, weight, BMI, FEV ${ }_{1}, \mathrm{FVC}, \mathrm{FEV}_{\mathrm{I}} / \mathrm{FVC}$, MIP, and MEP. Pearson's correlation was used to assess the relation between MIP and MEP with independent variables such as age, height, weight, $\mathrm{BMI}, \mathrm{FEV}_{1} \%, \mathrm{FVC} \%$, and $\mathrm{FEV}_{\mathrm{I}} / \mathrm{FVC} \%$.

\section{RESULTS}

A total of 99 known COPD male patients, who were clinically stable, completed the measurement process in this study. The mean age of the COPD population studied was $62.90 \pm 6.23$ years. PFT measured by spirometry showed a mean $( \pm \mathrm{SD}) \mathrm{FEV}_{1} \%$ of $47.81 \pm 23.9$, mean $( \pm \mathrm{SD}) \mathrm{FVC} \%$ of $63.99 \pm 22.08$, and mean $( \pm \mathrm{SD}) \mathrm{FEV}_{1} / \mathrm{FVC} \%$ of $67.60 \pm 21.99$. Maximum inspiratory and expiratory pressures were a mean $( \pm \mathrm{SD})$ $47.73 \pm 19.6$ and $60.76 \pm 11.6 \mathrm{~cm} \mathrm{H}_{2} \mathrm{O}$, respectively, [Table 1].

Pearson's correlation-coefficient was used to assess the relation between MIP and MEP with independent variables such as age, height, weight, $\mathrm{BMI}, \mathrm{FEV}_{1} \%, \mathrm{FVC} \%$, and $\mathrm{FEV}_{\mathrm{I}} / \mathrm{FVC} \%$ [Tables 2 and 3]. It was seen that MIP showed a highly significant correlation $(P<0.001)$ with both $\mathrm{FEV}_{1} \%$ and $\mathrm{FVC} \%$. The correlation between MIP and $\mathrm{FEV}_{1}$ shows a positive linear trend and more clustering of MIP toward $\mathrm{FEV}_{1}$ at $25 \%-75 \%$ [Figure 1]. MEP showed a highly significant correlation $(P<0.001)$ with weight, $\mathrm{FEV}_{1} \%$, and $\mathrm{FVC} \%$ and a moderately significant correlation $(P<0.05)$ with BMI [Table 3].

A positive linear correlation was seen between MEP and $\mathrm{FEV}_{1}$, and the MEP $P$ values were higher than MIP $P$ values [Figure 2]. A negative correlation existed between MIP and MEP with age [Figures 3 and 4]. With increase in age, there was a decrease in both MIP and MEP. According to

\begin{tabular}{|c|c|c|c|}
\hline & Mean \pm SD & Minimum & Maximum \\
\hline Age (years) & $62.90 \pm 6.23$ & 50 & 85 \\
\hline Height (cm) & $165.74 \pm 6$ & 140 & 177 \\
\hline Weight (kg) & $61.60 \pm 11$ & 30 & 120 \\
\hline $\mathrm{FEV}_{1}(\%)$ & $47.81 \pm 24$ & 20 & 127 \\
\hline FVC (\%) & $63.99 \pm 22$ & 28 & 135 \\
\hline $\mathrm{FEV}_{1} / \mathrm{FVC}(\%)$ & $67.60 \pm 22$ & 20 & 114 \\
\hline $\mathrm{MIP}\left(\mathrm{cm} \mathrm{H}_{2} \mathrm{O}\right)$ & $47.73 \pm 19.62$ & 18 & 127 \\
\hline $\mathrm{MEP}\left(\mathrm{cm} \mathrm{H}_{2} \mathrm{O}\right)$ & $60.76 \pm 11.64$ & 40 & 128 \\
\hline BMI $\left(\mathrm{kg} / \mathrm{m}^{2}\right)$ & $22.4 \pm 3.55$ & 10.73 & 41.52 \\
\hline
\end{tabular}

\section{Table 2: Correlation between maximum inspiratory pressure and age, height, weight, body mass index, forced expiratory volume in the $1 \mathrm{~s}$ percentage, forced vital capacity percentage, and forced expiratory volume in the $1 \mathrm{~s} /$ forced vital capacity percentage}

\begin{tabular}{lcc}
\hline Variable & \multicolumn{2}{c}{ MIP $\left(\mathbf{c m ~ H}_{\mathbf{2}} \mathbf{0}\right)$} \\
\cline { 2 - 3 } & $\boldsymbol{r}$ & $\boldsymbol{P}$ \\
\hline Age (years) & -0.051 & 0.613 \\
Height $(\mathrm{cm})$ & 0.194 & 0.054 \\
Weight $(\mathrm{kg})$ & 0.151 & 0.137 \\
BMI $\left(\mathrm{kg} / \mathrm{m}^{2}\right)$ & 0.101 & 0.318 \\
FEV $_{1}(\%)$ & 0.616 & $<0.001^{*}$ \\
FVC $(\%)$ & 0.535 & $<0.001^{*}$ \\
FEV $_{1} /$ FVC $(\%)$ & 0.128 & 0.207 \\
\hline
\end{tabular}

* Level of significance set at $P<0.05$. BMI: Body mass index, FEV : Forced expiratory volume in the $1 \mathrm{~s}$, FVC: Forced vital capacity, MIP: Maximum inspiratory pressure 
Nambiar, et al.: Respiratory muscle pressures in male COPD patients

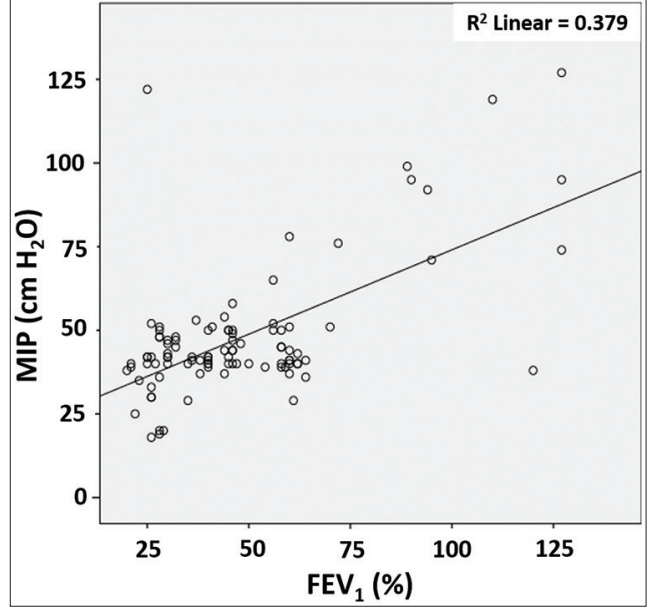

Figure 1: Scatter plot depicting the correlation between maximal inspiratory pressure and $\mathrm{FEV}_{1}$

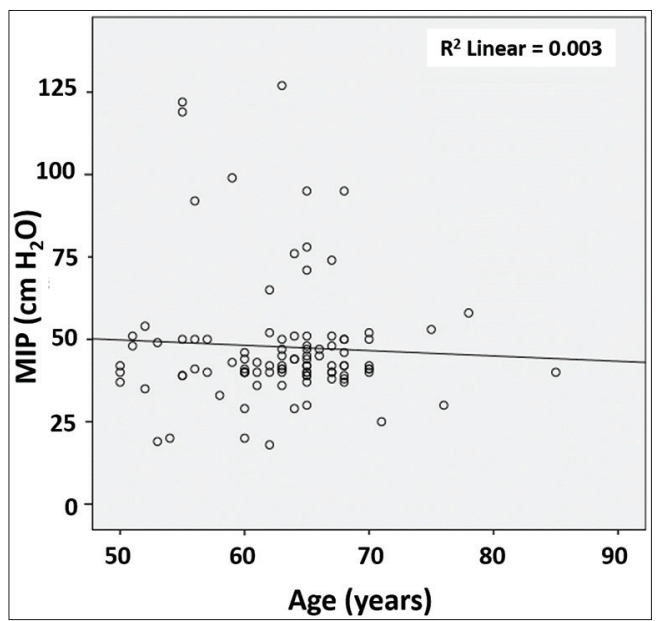

Figure 3: The correlation between maximal inspiratory pressure and age

the value of $\mathrm{FEV}_{1} \%$, the results revealed that $30 \%$ of COPD patients had very severe airflow obstruction $\left(\mathrm{FEV}_{1}<30 \%\right)$, $35 \%$ had severe airflow obstruction $\left(\mathrm{FEV}_{1} 30 \%-50 \%\right), 25 \%$ had moderate airflow obstruction ( $\mathrm{FEV}_{1} 50 \%-80 \%$ ), and $9 \%$ of patients had mild airflow obstruction $\left(\mathrm{FEV}_{1}>80 \%\right)$ [Table 4].

As the severity of airflow obstruction is progressively increasing, the value of MIP and MEP were significantly lowered in patients with severe and very severe airway obstruction with a statistically significant difference between the levels of airway obstruction concerning MIP value (F-test-29.31, $P<0.001$ ) and MEP value (F-test-15.67, $P<0.001)$ [Table 5].

It is seen from the box and error plot that there was a decrease in MIP and MEP with increasing severity of COPD [Figures 5 and 6]. There is a positive correlation between MIP and MEP [Figure 7].

\section{Discussion}

The results show that the MIP values among male COPD patients were much lower than their age-matched controls. ${ }^{[12]}$

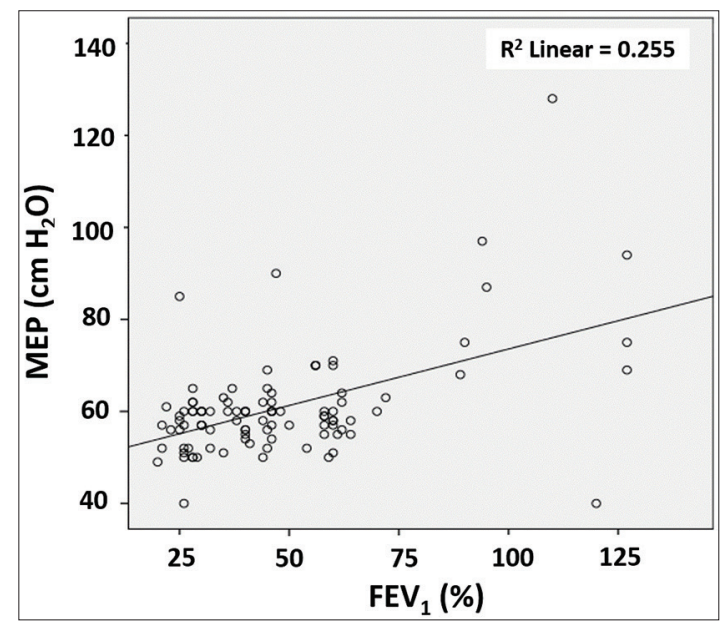

Figure 2: Scatter plot depicting the correlation between Maximal expiratory pressure and $\mathrm{FEV}_{1}$

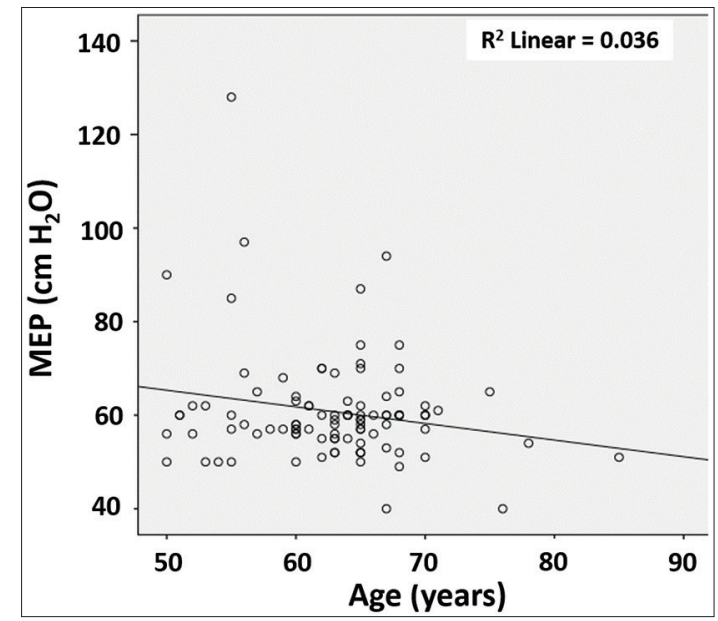

Figure 4: Scatter plot depicting the correlation between maximal expiratory pressure and age

Table 3: Correlation between maximum expiratory pressure and age, height, weight, body mass index, forced expiratory volume in the $1 \mathrm{~s}$ percentage, forced vital capacity percentage, and forced expiratory volume in the $1 \mathrm{~s} /$ forced vital capacity percentage

\begin{tabular}{lcc}
\hline Variable & \multicolumn{2}{c}{ MEP $\left(\mathbf{c m ~ H}_{\mathbf{2}} \mathbf{0}\right)$} \\
\cline { 2 - 3 } & $\boldsymbol{r}$ & $\boldsymbol{P}$ \\
\hline Age (years) & -0.190 & 0.059 \\
Height $(\mathrm{cm})$ & 0.172 & 0.089 \\
Weight $(\mathrm{kg})$ & $0.273^{* *}$ & $<0.006$ \\
BMI & $0.233^{*}$ & $<0.020$ \\
FEV $_{1}(\%)$ & $0.505^{* *}$ & $<0.001$ \\
FVC $(\%)_{\text {FEV }_{1} / \text { FVC }(\%)}\left(0.379^{* *}\right.$ & $<0.001$ \\
\hline
\end{tabular}

${ }^{*} * P<0.001,{ }^{*} P<0.05$. BMI: Body mass index, $\mathrm{FEV}_{1}$ : Forced expiratory volume in the $1 \mathrm{~s}, \mathrm{FVC}$ : Forced vital capacity, MEP: Maximum expiratory pressure

The MIP (inspiratory muscle strength) values were more affected when compared to MEP (expiratory muscle strength) 
values in COPD patients. There was a decline in MIP and MEP with increase in age.

MIP and MEP correlated with $\mathrm{FEV}_{1}$, i.e., when $\mathrm{FEV}_{1}$ reduced, MIP and MEP also reduced significantly. The results obtained in the present study were in parallel with some of the recent literature. In addition, it was seen that respiratory muscle weakness occurs early in COPD with a decline in MIP and MEP as the severity of the disease (GOLD Criteria) progressed. The results show that the MIP values among COPD patients were much lower than their age-matched normal people. However, the MEP values did not show much of a difference in the (60-70) years of age group. The MIP (inspiratory muscle strength) values were more affected when compared to MEP (expiratory muscle strength) values in COPD patients. According to a study done by Voicu et al., MIP was significantly decreased in moderate to severe stages of COPD which correlated with decreased effort capacity as measured by 6-min walk distance.

The lean body mass decreases with increase in the severity of the disease. Thus, there is decreased muscle strength which is induced by various factors such as oxidative stress, inflammatory status, metabolic and nutritional dysfunction, bed rest, and prolonged steroid treatment. ${ }^{[13]}$ MIP and MEP indicate the state of respiratory muscle strength and is related to the severity of COPD and spirometric indices.

MIP negatively correlated with age. Due to the aging process, there is a reduction in the diaphragm and respiratory muscle mass. Therefore, MIP was further compromised in COPD patients. ${ }^{[14]}$ Khalil et al. studied MIP and MEP in patients with COPD being $43.6 \% \pm 26.9 \%$ and $46.8 \% \pm 26 \%$, respectively, which was similar to this present study. ${ }^{[15]}$ It was concluded in

\begin{tabular}{|c|c|}
\hline Degree of airflow obstruction $(n=99)$ & Frequency, $n$ (\%) \\
\hline Mild $\left(\mathrm{FEV}_{1} \%>80\right)$ & $9(9.1)$ \\
\hline Moderate $\left(\mathrm{FEV}_{1} \%[50-80]\right)$ & $25(25.3)$ \\
\hline Severe $\left(\mathrm{FEV}_{1} \%[30-50]\right)$ & $35(35.4)$ \\
\hline Very severe $\left(\mathrm{FEV}_{1} \%<30\right)$ & $30(30.3)$ \\
\hline
\end{tabular}

a study done by Hans-Joachim Kabitz that inspiratory muscle strength decreases in COPD patients with increasing disease severity. This could be attributed to two factors: compromised diaphragmatic contractility in the early stages and further reduction in inspiratory muscle strength following hyperinflation in advanced COPD. All these lead to decreased exercise capacity, impaired gas exchange, and increased dyspnea. Thus, the two mechanisms responsible for decreased MIP in COPD are decreased diaphragmatic contractility which begins in the early stages of the disease, which is independent of hyperinflation, and second, decreased diaphragmatic force generation due to hyperinflation in severe to very severe stages of the disease. ${ }^{[16]}$

\section{Limitations of the study}

In this study, other factors, such as smoking, medication compliance, and comorbidities were not considered, which probably could have an influence on MIP and MEP.

\section{Conclusion}

COPD is a cause of respiratory muscle weakness and it occurs early in the disease. There is a decrease in respiratory muscle strength, especially inspiratory muscle strength (MIP) with progression of the disease.

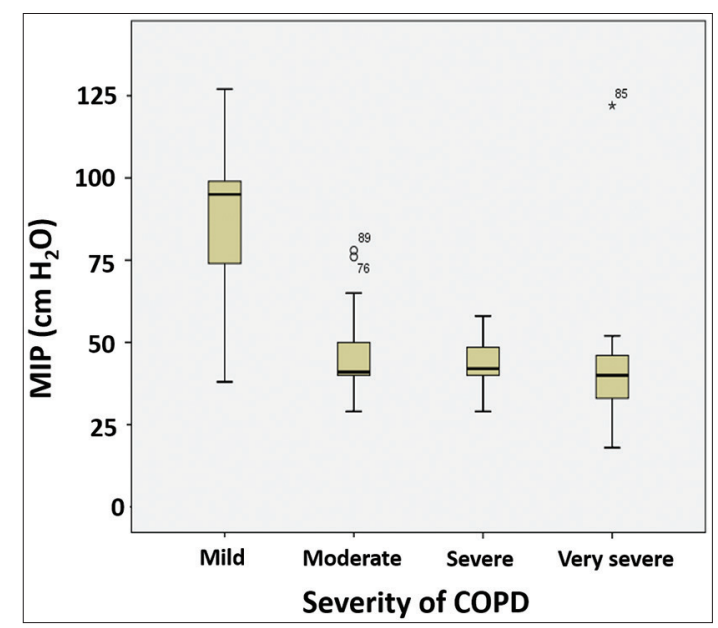

Figure 5: Box error plot showing the correlation between maximal inspiratory pressure and different stages of chronic obstructive pulmonary disease severity (GOLD criteria). 1 - Mild, 2 - Moderate, 3 - Severe, 4 - Very Severe

Table 5: Comparison between the chronic obstructive pulmonary disease subjects according to the level of severity concerning the maximum inspiratory pressure and maximum expiratory pressure $\left(\mathrm{cm}_{2} \mathrm{O}\right)$

\begin{tabular}{|c|c|c|c|c|}
\hline & \multicolumn{4}{|c|}{ COPD stage (GOLD criteria) } \\
\hline & Mild & Moderate & Severe & Very severe \\
\hline \multicolumn{5}{|l|}{ MIP } \\
\hline Range (mean $\pm \mathrm{SD}) *$ & $69.54-110.46(90 \pm 26.6)$ & $41.27-50.89(46.08 \pm 11.64)$ & $42.1-46.0(44.09 \pm 5.7)$ & $33.89-47.45(40.67 \pm 18.1)$ \\
\hline \multicolumn{5}{|l|}{ MEP } \\
\hline Range (mean $\pm \mathrm{SD}) *$ & $62.7-100.14(81.44 \pm 24.3)$ & $57.45-62.5(60 \pm 6.1)$ & $56.9-61.7(59.3 \pm 6.8)$ & $54.03-59.64(56.83 \pm 7.5)$ \\
\hline
\end{tabular}


Nambiar, et al:: Respiratory muscle pressures in male COPD patients

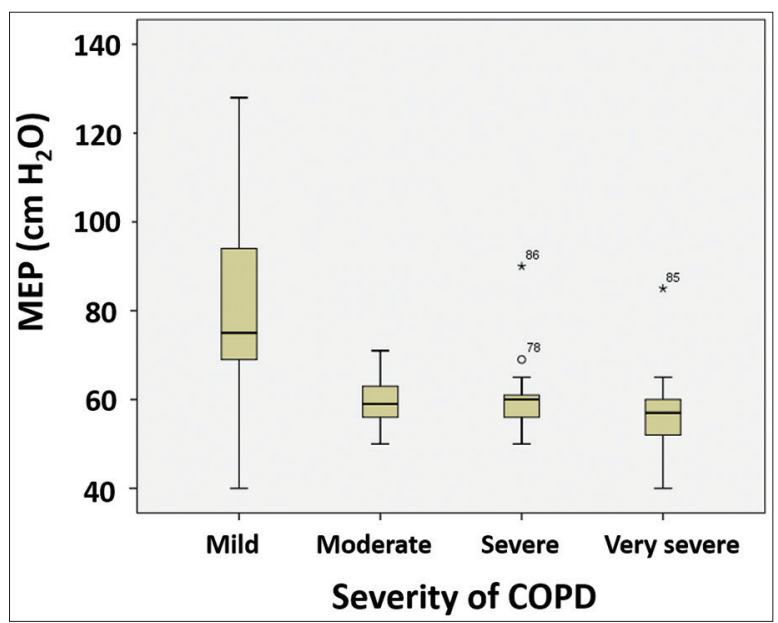

Figure 6: Box error plot showing the correlation between Maximal expiratory pressure and different stages of chronic obstructive pulmonary disease severity (GOLD criteria). 1 - Mild, 2 - Moderate, 3 - Severe, 4 - Very Severe

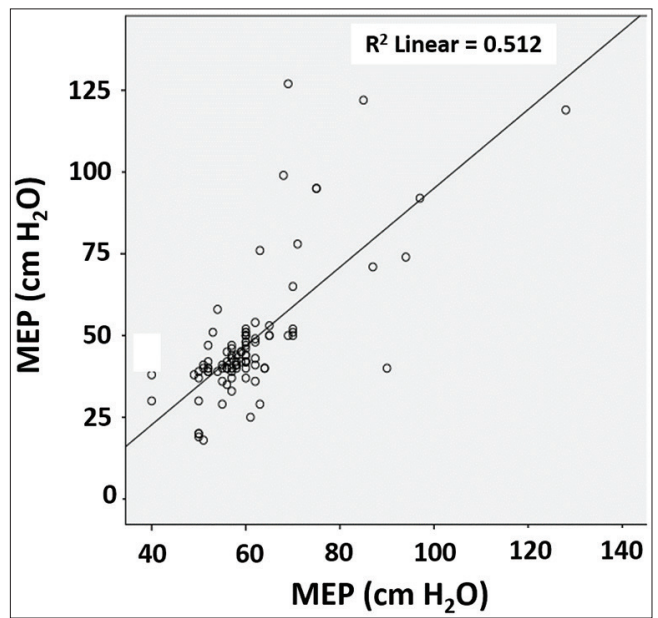

Figure 7: Scatter plot depicting the correlation between Maximal inspiratory pressure and Maximal expiratory pressure

\section{Implications}

Respiratory muscle strength assessment in the form of MIP and MEP should be carried out in a COPD patient, and thus, respiratory muscle training should be included in a pulmonary rehabilitation program.

\section{Financial support and sponsorship}

Nil.

\section{Conflicts of interest}

There are no conflicts of interest.

\section{REFERENCES}

1. Barnes PJ. Chronic obstructive pulmonary disease. N Engl J Med 2000;343:269-80.

2. Skeletal muscle dysfunction in chronic obstructive pulmonary disease. A statement of the American thoracic society and European respiratory society. Am J Respir Crit Care Med 1999;159:S1-40.

3. Gosselink R, Troosters T, Decramer M. Distribution of muscle weakness in patients with stable chronic obstructive pulmonary disease J Cardiopulm Rehabil 2000;20:353-60.

4. Troosters T, Pitta F, Decramer M. Respiratory muscle assessment in pulmonary rehabilitation. In: Donner CF, editor. Pulmonary Rehabilitation. London: Hodder Arnold; 2005. p. 69-79.

5. Orozco-Levi M. Structure and function of the respiratory muscles in patients with COPD: Impairment or adaptation? Eur Respir J Suppl 2003;46:41s-51s.

6. Celli BR, Cote CG, Marin JM, Casanova C, Montes de Oca M, Mendez RA, et al. The body-mass index, airflow obstruction, dyspnea, and exercise capacity index in chronic obstructive pulmonary disease. N Engl J Med 2004;350:1005-12.

7. Marchand E, Decramer M. Respiratory muscle function and drive in chronic obstructive pulmonary disease. Clin Chest Med 2000;21:679-92.

8. Terzano C, Ceccarelli D, Conti V, Graziani E, Ricci A, Petroianni A, et al. Maximal respiratory static pressures in patients with different stages of COPD severity. Respir Res 2008;9:8.

9. KlimathianakiM,VaporidiK, GeorgopoulosD. Respiratory muscledysfunction in COPD: From muscles to cell. Curr Drug Targets 2011;12:478-88.

10. Bégin P, Grassino A. Inspiratory muscle dysfunction and chronic hypercapnia in chronic obstructive pulmonary disease. Am Rev Respir Dis 1991;143:905-12.

11. Zielinski J, MacNee W, Wedzicha J, Ambrosino N, Braghiroli A, Dolensky J, et al. Causes of death in patients with COPD and chronic respiratory failure. Monaldi Arch Chest Dis 1997;52:43-7.

12. Nambiar VK, Ravindra S. Maximal respiratory pressures and their correlates in normal Indian adult population: A cross-sectional study. Int J Physiother Res 2015;3:1188-96.

13. Tudorache V, Oancea C, Mlădinescu OF. Clinical relevance of maximal inspiratory pressure: Determination in COPD exacerbation. Int J Chron Obstruct Pulmon Dis 2010;5:119-23.

14. Hafez MR, Eisheikh RM. Assessment of the respiratory muscles function in COPD patients. Egypt J Hosp Med 2012;49:661-71

15. Khalil M, Wagih K, Mahmoud O. Evaluation of maximum inspiratory and expiratory pressure in patients with chronic obstructive pulmonary disease. Egypt J Chest Dis Tuberculosis 2014;63:329-35.

16. Kabitz HJ, Walterspacher S, Walker D, Windisch W. Inspiratory muscle strength in chronic obstructive pulmonary disease depending on disease severity. Clin Sci (Lond) 2007;113:243-9. 